\title{
Research Paper on i-Residency
}

\author{
Bhandari R. R. \\ Assistant Professor \\ SNJB's KBJ COE, Chandwad
}

\author{
Bora M. S. \\ Student \\ Department of Computer \\ Engineering
}

\author{
Chordiya R. A. \\ Student \\ Department of Computer \\ Engineering
}

\author{
Chhajed R. M. \\ Student \\ Department of Computer \\ Engineering
}

\author{
Bedmutha T. V. \\ Student \\ Department of Computer \\ Engineering
}

\begin{abstract}
The aim is to develop an application which will provide the functionality to manage regular operations of the residential apartments. The main objective of the project is to develop the application software for the different apartments which will be useful for all of them. Working efforts of the members and the managing body of the apartment will be reduced to maintain the society. It mainly supports in replacing the traditional manually working process by the new computerized system. This application will be helpful to them to store monthly basis transactions as well as some daily transactions in the very effective manner which will be saving of the money also it will save the energy and valuable time of all the members.
\end{abstract}

This application will be able to maintain all the statistics and history of the records of the monthly maintenance, purchase, etc. Thisproject includes different parts as like billing \& accounting, online voting, light automation, and help desk.

\section{Keywords}

Push Notification Technology, Arduino Circuit Board, ESP8266 board (wifi sensor).

\section{INTRODUCTION}

Managing and Controlling Residential Society's manually is a tough task for the members of the Society committee. Many obstacles come in frontofthe members and also the peopleswho live in thatsociety. So the new and unique way to managingthe society istouse one of the Smart society management tools available in the market.

i-Residency is one of the applications for managing the society in a smart way. i-Residency is the smart application used in the residential societies by the peoples of the society for the purpose of managing the society. In which all the work will be done through the application instead of the doing it manually.

i-Residency integrates various features of managing a society such as managing billing and accounting, managing events, managing day-to-day operations. i-Residency is offered as a hosted solution with less infrastructure by the society. iResidency can be used by anyone associated with a residential society. i-Residency will provide the great features to the team maintaining the apartment billing and accounting. Some of the alternate society managing tools in the market are like Apartment Adda, Society123, Society Run, and Apartment Sathi.Features of the above alternatives as like:
- Accounting in which all the accounting facilities of the complex are maintained

- Member details has all the detailed information of the society members which is accessible only to the authorized society members

- $\quad$ Parking lot management in which parking slots are allocated to all the members systematically

- Event calendar which shows all the events date wise and Reminders which reminds the members time to time

- Society photo gallery which contains photos of the society and some good events

- Notice Board which gives daily important notices on our mobile phone instead on writing it on Blackboard

Following are some features of the i-Residency tool:

- Society Data Management

- Society billing and Accounting

- Community Collaboration

- Online voting for committee

- Event management

- Inventory Management

- $\quad$ Light Automation system

- Help Desk

Society data management includes all the data storage of the society's data such as important documents, all members details. It also contains all the information of each of the flat in the apartment.

Society billing and accounting includes all the tasks of the accounts in which all the daily or monthly basis transactions are maintained. In this, the secretary will manage all the monthly maintenance and other transactions such as other stuff needed in the apartment.

Online voting is done by all the members of the apartment for selecting the authorized managing body for managing the apartment. All the members in the apartment of each flat will have to give avote for the post of managing bodies such as secretary, treasurer, and chairman. 
In Community collaboration, Different meetings will be arranged and all the notifications are given by the secretary. If any member has any complaint regarding any issue in the apartment then they can do complaint by using the option which will be provided in this module.

Different Events will be managed in the society by the committee using this application. When any of the events will be there then the secretary can call the meeting for the arrangement.

Inventory management will manage all the things which have been purchased for the apartment.

Lights on the parking side and all the open spaces and corridors in the apartment building will get automatically switched on or off using the Arduino kit and ESP8266 controller. This will work very efficient in order to save energy and money.

If any of the members needs some help regarding their flat such as electrician or plumbing then they will get help in the form of contact number or address.

\section{LITERATURE SURVEY}

The urban population is increasing by many folds every decade. Higherstandards of living, greater.The urban population is increasing by many folds every decade Higher standards of living, greater exposure, fatter salary package and attractive lifestyle is making youth migrate from villages to cities.

In metro cities, the ratio of people to the land-living available can never be stable. Leave aside extensive towers, in metro's even owning a small flat is forbidding and a luxury that not all can afford.

As we know, with the space crisis increasing by leaps and bounds, more and more high-rise buildings are coming up to accommodate the ever Increasing population.

As there are many software's that are helpful for managing the society for various tasks some of them are defined here.

Apartment Add:-The main aim of Apartment Adda is to boost infrastructures among residents, facility management, and accounting personals.

The features of this system are:

- Involuntary maintenance billing

- User gets due notice SMS's

- In case of any difficulties, you can always contact the helpline.

- It is possible to view and publish various reports.[1 ]

Society 123:-This software manages the accounting and checking essentials of landowners, trade estates, builders and developers.

The features of this software are:

- Bill generation.

- Automatic bill delivery via e-mails.

- Managing tasks, meetings, registers, tasks, complaints, compliances, circulars and events.

- $\quad$ Alerting the recipients of pending bills by SMS. [2]
Smart Society :- This software facilitates enhanced communication between the members, sharing of pictures and documents, raising their opinion on various issues, keeping a record of notices, dues, and payment, decreasing paperwork and having clearness in all transactions.

The features of this software are:

- The society members can share their opinions, pictures, and thoughts by polls.

- It allows members to buy and sell things.

- Check for dealers and service providers.

- $\quad$ Enhanced communication. [3]

Apartment Sathi :-This software manages the accounting and checking essentials of landowners, trade estates, builders, and developers. The features of this software are:

- Communication application

- Management applications

- Accounting applications [4]

Real-time System:

MalpaniSaffron :-This residency is located at Nashik at Pathardi Fata where at most 50-60 flats are available wingwise.

The natural features in this residency which are available presently are:-

Fire system for each section is available.

- Parking slots for the flat owners and also for the guest is allotted and back-to-back parking is given.

- For the master bedroom, the solar system is present.

Hari Om Residency

This residency is also located at Nashik at Indira Nagar and construction is done by Kabra groups in this 4 sections are present.

The natural features of this residency which presently available are:

- Water Management: Devices are present.

- Parking slots for flat holders only.

- Bills are paid by yourself.

\section{PROPOSED SYSTEM}

In every housing society, there are volunteers who manage various sections like accounting, expense payment, calculating interest, etc. However, with the daily travel cramps and work pressure, it becomes increasingly tedious to manage the above-said functions.

This is where we come to your rescue with an i-Residency Software which provides below features:-

\section{Community Collaboration}

Society relatedcomplaints willbe given in this module by the member of the society and the proper action will be taken on the complaint and also the agenda of the meeting will be given through notification. 


\section{Society data management}

Society data management will maintain all the important documents which are related to the apartment with the respective flats.

\section{Society Billing and Accounting}

Society billing and accounting has maintain and controlling all account information and bills of services. The secretary and treasurer have highest priority for this section .monthly bill automatic generated and yearly graph are display to all members.

society have their society account in which all members add deposit the maintenance cost and bills are paid by account balance. The paid bill send to members and stored in database.

\section{Society Helpdesk.}

In helpdesk all the details of the services member which are available in apartment are maintained.

\section{Online Voting for the committee}

Society online voting is having the counting of the votes for the members which are represented for various post has to be vote online

\section{Inventory Management}

In this the items which are needed in the apartment for various purpose their counts and records will be maintain.

\section{Event Management}

Event management will have common as well as personal event record maintain the user has to book the place and has to send date and time and also has to pay the advance payment for the personal event.

\section{Light Automation.}

Controllable lights using phone anywhere in the world. [5]

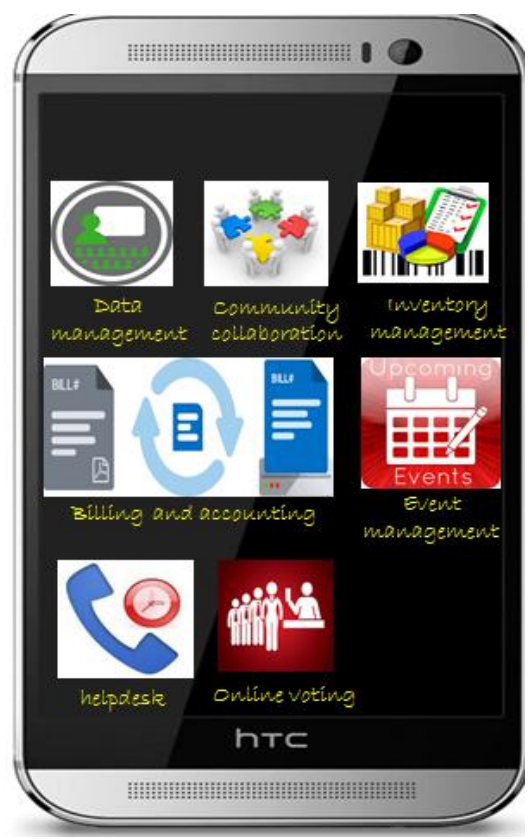

Figure 1. Proposed System

\subsection{System Architecture:}

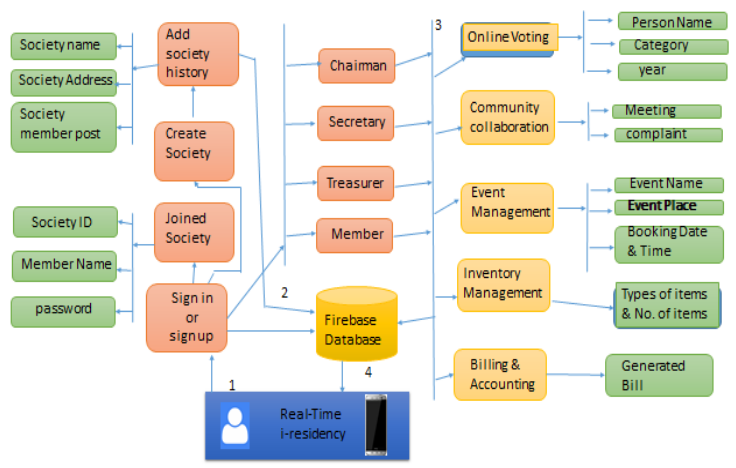

Figure 2.System Architecture

1. 1.Once the secretary of the society gets into the application, he will get options like "Create Society" and "Join Society". Then he will click on "Create Society" to add his society in that application. He will enter the necessary information which is by force required of his society for registration in the application and will in return get one single ID of that society which hewill provide that society to every member get an account in that request.

2. Secretary will have rights to add or remove the members of that society. As the members, enter in the application will haveto click on "Joint Society" and Enter his own informationwith thatunique ID which he will get from secretary to identify that member either he is of that society or he is creating a fake account in that society.

3. Secretary will have right to use to all of the features like Billing and Accounting, Community Collaboration, Inventory Management, and all of the others.

4. 4.A Treasurer who is another important managing body member will have main access to Billing and Accounting and Event Management. He will be the only authorized person to do all the transactions related to society. Whichever events will be there, will be handled by the treasurer from arranging a meeting for the event to conclude that event.

5. Chairman is the another important person of the managing body which will only observe all the actions silently without disturbing anything. If whatever will go wrong then he will suggest that to the secretary.

6. Members are also the users of the society who are living in that society. They will get notifications forward by the secretary or the treasurer. They will have choices to make a complaint if they have any difficulty. 


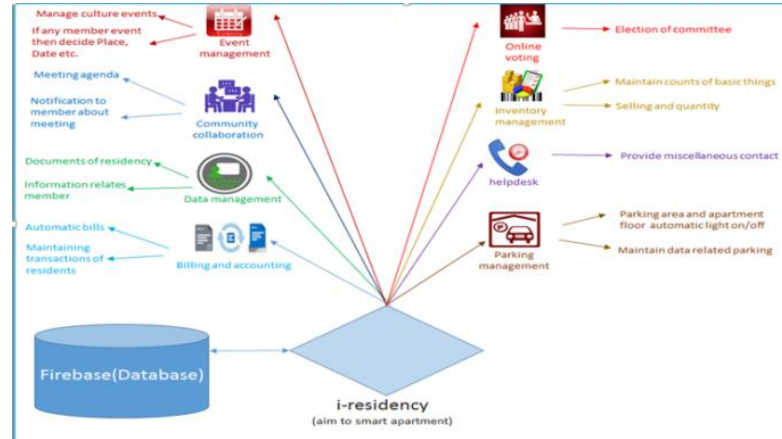

Figure 3.Working Model

\subsection{User Interface}

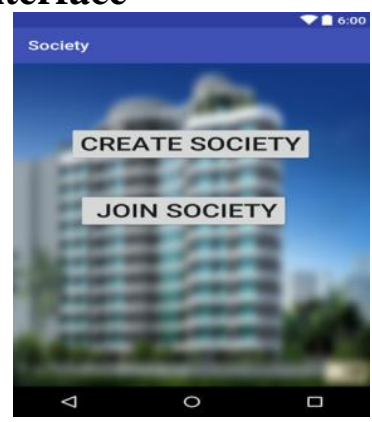

Figure4.Front View
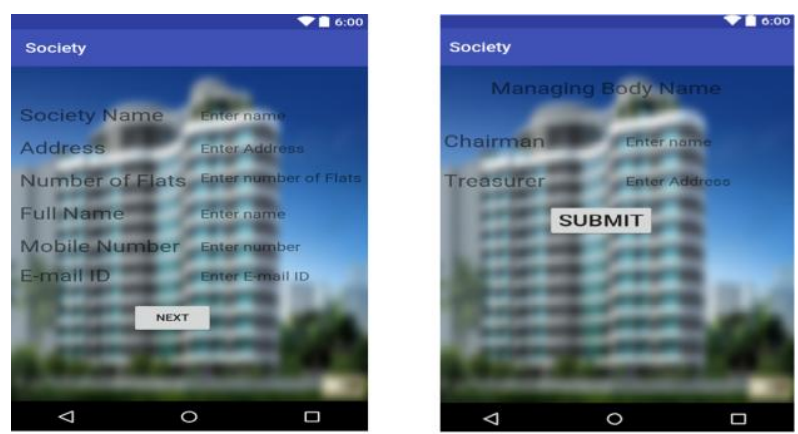

Figure 5. Information Filling\&Login

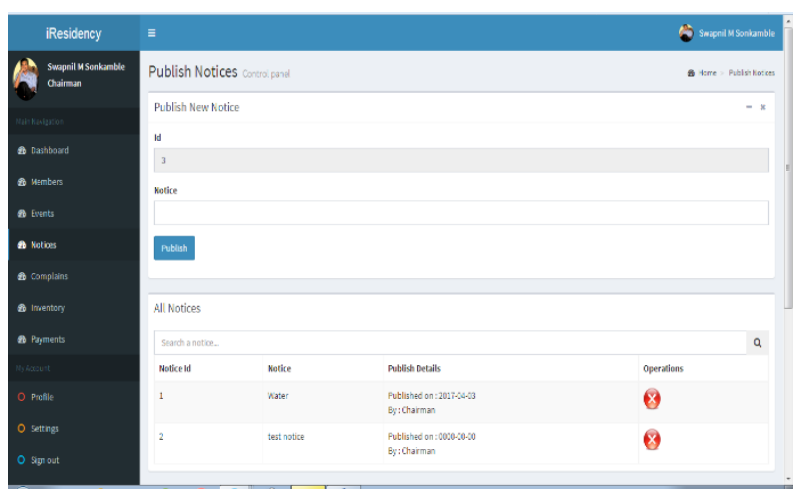

Figure6. Admin Panel

\subsection{Implementation of Light Automation}

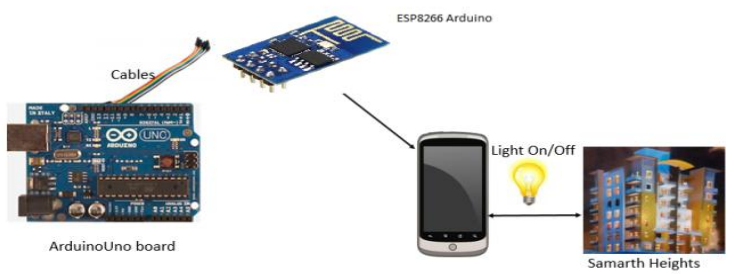

Figure 6.Light Automation Working

Light automation code:

// Your WiFi credentials.

// Set password to "" for open networks.

charssid[] = "Ashwini";

char pass[] = "ashu1993";

void $\operatorname{setup}()$

\{

Serial.begin(9600);

Blynk.begin(auth, ssid, pass);

\}

void $\operatorname{loop}()$

\{

Blynk.run();

\section{CONCLUSION}

By considering all the existing system we conclude that the proposed system will have the features newly implement which will play the vital role in making the society features such as online voting and light automation which helps to save and in directing helps to the environment conservation.

Further we will also include automatic gate security whichtracks the record of visitors who visit that society.

This application is user friendly and can be used by all in quick manner which proves a unique solution for the all residencies

\section{REFERENCES}

[1] https://www.google.co.in/?gfe_rd=cr\&ei=AkPfWLCcB6 fT8gfi6p6QDQ\&gws_rd=ssl\#q=Apartment+Adda+\&*

[2] http://app.society $123 . c o m /$ society $123 / \operatorname{login} / \operatorname{Login} A c t i o n$. do?doLogin=yes

[3] http://smart-society.co.in/

[4] http://www.moneycontrol.com/news-topic/apartmentsathi/

[5] https://electrosome.com/home-automation-arduinoesp8266 